\title{
A racionalidade nutricional e sua influência na medicalização da comida no Brasil
}

\author{
The nutritional rationale and its influence \\ on the medicalization of food in Brazil
}

\author{
Marcia Regina Viana ${ }^{1}$ \\ Alden Santos Neves ${ }^{2}$ \\ Kenneth Rochel Camargo Junior ${ }^{3}$ \\ Shirley Donizete Prado ${ }^{4}$ \\ André Luis Oliveira Mendonça ${ }^{3}$
}

${ }^{1}$ Universidade Federal do Rio de Janeiro. Av. Aluízio da Silva Gomes, Granja dos Cavaleiros. 27930-560 Macaé RJ Brasil.

marcianutrifil@gmail.com

${ }^{2}$ Coordenação de Nutrição,

UniFOA. Volta Redonda RJ

Brasil.

${ }^{3}$ Instituto de Medicina

Social, Universidade do

Estado do Rio de Janeiro

(UERJ). Rio de Janeiro RJ

Brasil.

${ }^{4}$ Instituto de Nutrição,

UERJ. Rio de Janeiro RJ

Brasil.

\begin{abstract}
This is an article based on a theoretical and conceptual reflection on the concept of nutritional rationale and its relation to the medicalization of food. The objective is to highlight the influence that eating habits suffer from the alleged condition of supremacy that science holds, which proclaims the need for health in its discourse. Based on the assumption of nutritional rationale as an eating obligation, it is assumed that it is responsible for the process of the medicalization of food. This is achieved by disqualifying the individual from self-care in terms of food, instilling the idea of the risk that comes from supposedly inadequate eating habits and fomenting the idea that to eat well is to eat accordingly to scientific principles. The dissemination of scientific studies and the results of research to the general public reveals the part played by eating in promoting a state of "better" health at the expense of the existentiality of food and its role as the aggregator in intersubjective relations.
\end{abstract}

Key words Eating habits, Nutritional rationale, Healthy eating, Medicalization
Resumo Ensaio baseado em reflexão teórico conceitual acerca do conceito racionalidade nutricional e sua relação com a medicalização da comida, onde se buscou apontar a influência que práticas alimentares sofrem do suposto estado de supremacia que a ciência detém, a qual sugere em seu discurso a necessidade de saúde. A partir do pressuposto da racionalidade nutricional como dever comer, supõe-se que este participa do processo de medicalização da comida ao descredenciar o sujeito do autocuidado alimentar, engendrar a ideia de risco de suposta alimentação inadequada e fomentar a ideia de que comer bem é comer de acordo com princípios científicos. A disseminação para o grande público de estudos científicos e os resultados de pesquisas relevam o papel da racionalidade nutricional na promoção de "melhor" saúde em detrimento da existencialidade da comida e de seu papel agregador nas relações intersubjetivas.

Palavras-chave Práticas alimentares, Racionalidade nutricional, Alimentação saudável, Medicalização 


\section{Introdução}

A preocupação com a alimentação tornou-se hábito constante em diferentes segmentos da população. Muitos fenômenos parecem estar associados à acentuada racionalidade em torno do que comer: a imensa oferta de alimentos industrializados, a grande complexidade dos rótulos de alimentos, as políticas públicas que tomam a concepção de alimentação saudável como um dos meios de promoção da qualidade de vida, a galopante inovação na criação de sistemas alimentares cada vez mais sofisticados, crescentes informações em torno da funcionalidade dos alimentos e o que tudo isso proporciona: o incomensurável acervo de informações sobre o assunto.

Estudos de Beardsworth e Keil ${ }^{1}$ apontam esta tendência ao assinalar a marcante vinculação entre a racionalização da dieta e concepções racionais de saúde. Nestlé ${ }^{2}$ considera que o tema da alimentação saudável é eminentemente político e insinua-se a partir da pressão da indústria de alimentos e de sua publicidade em consolidar um conceito de alimentação saudável através de seus produtos. As informações contidas nas embalagens de alimentos processados e no discurso da mídia destes alimentos sustentam seus argumentos de convencimento com ideias de saúde e de alimentação saudável, fato que incita no consumidor maior racionalidade para a aquisição de alimentos, levando-o a apropriar-se de determinados conceitos presentes nas informações de embalagens e nos discursos da mídia - conceitos que passam a fundamentar suas práticas alimentares.

Estes elementos levam a considerar que a atitude (racional) frente à comida ganhou dimensão aumentada, colaborando no processo de medicalização, conceito essencial na sociologia médica, estudada desde meados do século passado por estudiosos como Zola, Foucault e Illich. Nos idos de 1980, muitos estudiosos discutiram o tema. Mais recentemente, destaca-se a marcante definição de Peter Conrad: "um processo pelo qual problemas não médicos passam a ser definidos e tratados como problemas médicos, comumente em termos de doença e distúrbios”3. Por ser um conceito abrangente, seu sentido apresenta proximidade com ideias diferentes entre si: a não competência do sujeito sobre cuidados de saúde a si mesmo, a caracterização como doença de estados antes tomados como "normais", a proliferação de drogas que pretendem solucionar deficiências ou melhorar performance.

Um dos "resultados" que o processo de medicalização nos trouxe foi a "tirania da saúde" que propõe a necessidade do indivíduo estar sempre saudável e a querer buscar esse espectro de "saudabilidade" em quase toda a extensão da existência. Dentro deste processo, engendram-se grandes especulações acerca do padrão alimentar facilitador do melhoramento desta performance existencial.

Por conta desse cenário, suspeita-se que a racionalidade nutricional colabora no processo de medicalização da sociedade nos seguintes pontos: 1) descredenciamento do sujeito em escolher a própria comida e por isso sentir-se impelido a buscar maiores informações acerca do tema; 2) elevação de uma suposta má alimentação a uma funcionalidade negativa por atribuir-lhe excessiva responsabilidade em consequências nefastas à saúde sem levar em conta outras particularidades individuais; e 3 ) na ideia de que comer bem é comer de acordo com princípios científicos, mesmo que não tenha se observado qualquer "descompensamento" alimentar ou dietético nutricional.

Este estudo pretende apontar a influência que as práticas alimentares sofrem do suposto estado de supremacia que a ciência detém, a qual sugere em seu discurso a necessidade de saúde; investir na compreensão do que seja racionalidade nutricional e evidenciar como esta tendência alimentar participa do processo de medicalização da sociedade pela da alimentação, alertando que diferentes expertises se apropriaram do discurso sobre alimentação adequada visando objetivos diferenciados.

\section{Racionalidade e racionalidade nutricional}

Para esclarecer o conceito de racionalidade nutricional, esforçamo-nos em compreender o sentido que os termos constituintes da expressão trazem originalmente. Primeiramente foi feita consulta ao verbete racionalidade em dicionário de filosofia por entendermos ser esta a disciplina que se ocupa de definições conceituais. Jean-Pierre Dupuy ${ }^{6}$ pondera que "a identificação da moral com a razão é muito mais comum” e aproxima a racionalidade da teoria da escolha racional. Sentimo-nos inclinados a pensar a racionalidade e, por tabela, a expressão racionalidade nutricional conforme a argumentação de Dupuy, principalmente pela vinculação desta qualidade humana com a capacidade de decidir e também porque pensamos ser preponderantemente a ideia central contida nesta expressão.

Este entendimento fortalece a tendência de pensar a racionalidade nutricional também apreciada pela Ética, principalmente por este concei- 
to implicar ou pressupor escolhas alimentares. É de domínio popular o ditado de que "você é o que você come", emprestando a esta afirmação a lógica de constituição do sujeito pelo alimento. Assim, a qualidade do que se come implicaria a qualidade do que se é. A escolha do que comer parece vincular-se ao projeto de vida subjetivo e, por isso, alimentos que ofereçam a oportunidade de "galgar" um espaço supostamente mais valorizado do que aquele no qual o sujeito se acredita, pode exercer atração e definir uma prática alimentar. Dado este fato, pensa-se que a atitude racional guarda em si certo "charme" sedutor frente às pessoas que acabam por exibir maior racionalidade em relação ao que comer. Em outras palavras, a adoção de determinados tipos de alimentação pode significar o desejo de pertencer a um grupo determinado.

É importante considerar também que a categoria racionalidade, e atreladas à ela as categorias razão e racional implicadas neste estudo, adquiriu sentido peculiar, fundado tanto em seu percurso histórico quanto na convenção de seu uso no senso comum. A expressão “ter razão” está aliada à ideia de estar de posse da verdade, e uma vez com esta, desvendar ou "apossar-se" da realidade. A razão é considerada o instrumento de verdade, sendo sua função a apreensão da realidade $^{7}$. A racionalidade como constituinte da verdade soberana é conquistada na Era das Luzes, quando é estabelecida a razão crítica que colocava em questão tudo aquilo que não resistisse à prova racional. Proposições nomológicas (baseadas em leis naturais) sustentavam a compreensão dos fatos e isto suscitou atribuir como objetos do conhecimento apenas aqueles que podiam ser descritos matematicamente ${ }^{8}$. Características apreendidas sensorialmente (como cor, temperatura entre outras) eram consideradas “subjetivas" e, por isso, não passíveis de serem submetidas às leis ${ }^{9}$. Ainda sobre o Iluminismo Moderno, além de sobrepujar a racionalidade, este momento histórico favoreceu também a tendência emancipatória de autonomia subjetiva, esta proporcionada pelo juízo crítico, o qual incidia tanto no âmbito teórico quanto no prático. Ao requerer o crivo da razão, os iluministas proporcionaram a liberdade de pensamento, exigindo autonomia do sujeito nos campos dos costumes, da política e da economia. O sujeito emerge de um estado de submissão religiosa e política, esta última ainda ligada à graça divina, admitindo ideais de felicidade e liberdade como possibilidades de realização ${ }^{10}$.

Realizamos um levantamento bibliográfico da produção acadêmica acerca do conceito racio- nalidade nutricional, combinando os termos "racionalidade nutricional", "racionalidade alimentar", "alimentação racional” e "nutrição racional”, restrito à base de dados da Biblioteca Virtual de Saúde (BVS) pelo relevante impacto como fonte de pesquisa. Foram recuperados documentos do período de 1988 a 2012.

A primeira chave de busca foi "racionalidade nutricional", a qual recuperou cinco resultados, dos quais o primeiro se referia a estudo específico do PNAE (Programa Nacional de Alimentação Escolar); o segundo tomava "por objeto a existência pouco estudada de outras racionalidades nutricionais distintas da biomédica, comumente inseridas nas chamadas práticas e medicinas tradicionais e/ou complementares" ${ }^{11}$, sendo este o mais próximo do nosso objeto de estudo. Nesse texto, Navolar et al. ${ }^{11}$, ao proporem a modalidade NCI - Nutrição Complementar Integrada, já sinalizam para a necessidade de "relativização do modelo dominante e da perspectiva energéticoquantitativa da Nutrição que embasam a noção moderna do que é um alimento saudável". O terceiro artigo era um trabalho vinculado à Síndrome de Down. O quarto e quinto artigos diziam respeito à alimentação no processo de doença.

A segunda chave de busca foi "racionalidade alimentar", que mostrou quatro resultados, os mesmos recuperados pela chave anterior. A próxima chave de busca foi "alimentação racional", a qual não encontrou nenhuma resposta. A chave de busca "alimentação" and "racional" recuperou trinta resultados, dos quais apenas três artigos se enquadravam no escopo do estudo atual. A última chave de busca foi a combinação "nutrição" and "racional", com trinta e oito resultados, sendo apenas seis vinculados ao objeto desse estudo e desses seis, três já haviam sido recuperados pelas buscas anteriores.

No cenário internacional, destaca-se na França o estudo Du discours nutritionnel aux représentations de l'alimentation ${ }^{12}$, realizado pelo Centre de Recherche pour l'Étude et l'Observation des Conditions de Vie (CRÉDOC), com o principal objetivo de refletir sobre a pressão que a informação nutricional tem exercido sobre o consumo de alimentos considerados saudáveis, analisando a relação entre o discurso nutricional (discourse nutritionnel) e comida dos últimos 20 anos a partir da questão “o que é comer bem?”. Esse estudo evidenciou que o discurso nutricional é fundado: em prescrições religiosas que se referem à tradição (passado), em disposições sociais vinculadas ao prazer de comer (presente) e em prescrições biomédicas que se referem à saúde (futuro), este 
último aspecto já apresentando certo estreitamento com a medicalização da comida.

Annemarie $\mathrm{Mol}^{13}$ chama a atenção para as "ontonormas" em seu artigo Mind your plate!, termo para o qual não propõe definição, mas que sugere a ideia de escolha do alimento a partir de sua adequação, tanto ao grau de informação do comensal quanto ao seu estilo de vida. Tratar-se-ia, portanto, do reconhecimento de algum grau de racionalidade subjetiva ao escolher o que comer.

Não menos importante e reconhecidamente muito influenciador, o termo nutricionismo é utilizado por Michael Pollan ${ }^{14}$ como referência ao aspecto ideológico da exacerbada racionalidade desenvolvida em torno da alimentação e mostra como principal apelo desta ideologia identificar o alimento como somatório de nutrientes, minimizando ou mesmo subtraindo os componentes socioculturais das comidas e da comensalidade.

\section{O conceito de racionalidade nutricional}

Para nortear o estudo, partimos de um pressuposto elaborado por nós de que a racionalidade nutricional se refere às práticas alimentares atentas ao permanente cuidado em manter na alimentação o equilíbrio de nutrientes, em detrimento do prazer de comer e dos valores com que a alimentação marca o convívio social a ele associado. Tais práticas alimentares sinalizam preocupações centradas no "consumo racional de alimentos" e com a "alimentação balanceada". Essa ideia reduz a relação entre valor nutricional do alimento e saúde como única causalidade ou a mais valorizada pela tradição do conhecimento científico, por se acomodar muito bem na lógica do processo de verificação de verdades proposto pelo método (científico). A despeito desta relação causal ser necessária ou não, os valores que norteiam as práticas alimentares parecem se legitimar na ideia de que a alimentação balanceada é o resultado apenas de consumo de nutrientes adequados, sem considerar os aspectos que envolvem o preparo e o consumo de comidas. A ideia-força que fundamenta o conceito ora estudado não considera o aspecto socioantropológico da alimentação, aspecto que tem despertado grandes e profícuas discussões e que mostram sua "íntima relação com a reprodução biológica e social dos grupos humanos"15.

Neste ponto é mister considerar importantes diferenças que insurgem entre os termos comida, alimento e nutriente. A definição que adotamos para comida é o que se coloca no prato e com este se senta à mesa, o que implica em algum grau de resolução subjetiva e intersubjetiva. Nesta intersubjetividade subjazem elementos já ressaltados por Carvalho et al. ${ }^{16}$ quanto à função cultural que a comida agrega como identidade de um povo. $\mathrm{O}$ alimento está mais próximo do contexto da economia de mercado, da produção e da distribuição de commodities, como também de cuidados relacionados à segurança e inocuidade de seu consumo, estando na ordem do pensamento sistemático e estratégico da vida urbana. O nutriente fica sob a égide da ciência e é conhecimento específico advindo de seu método.

A investigação que propicie a amplitude pretendida para o entendimento dessa problemática reclama visitas à filosofia, à sociologia, à história, à antropologia, à economia entre outras disciplinas, e por este motivo não soou estranho durante a revisão bibliográfica recuperar documentos provenientes de diversos campos científicos, como Administração, História, Geografia, Psicologia e Educação.

Alguns documentos evidenciaram traços históricos definitivos para a base de algumas práticas alimentares atuais, como a importância que a industrialização de alimentos mostrou nos anos de 1920. O trabalho de Sant'Anna ${ }^{17}$ aborda esta temática na sociedade paulistana, ao mencionar a realização da primeira exposição industrial de laticínios em 1925, no Palácio das Indústrias. "A alimentação foi ali considerada uma questão de afirmação das potências regionais e, logo a seguir, de identidade das raças e da Nação". Neste excerto é notória a vinculação da alimentação com a eugenia.

Outros documentos tratam da temática no Brasil a partir de 1940, período em que surgiram instituições relevantes e pertinentes ao objeto estudado, como a criação do salário mínimo, do SAPS (Serviço de Alimentação da Previdência Social), dos cursos de graduação em Nutrição ${ }^{18}$. O estudo de Lima ${ }^{19}$ informa que a alimentação começa a ser observada sob a nomenclatura de racional quando passa a ser entendida como fonte de energia e nutrientes e quando passa a compor a agenda política do Estado.

É importante a reflexão acerca da diferença encontrada entre as expressões "racionalidade alimentar" e "racionalidade nutricional". A primeira surge como o modelo de dieta a seguir, principalmente em função de objetivos dominantes, como os estudos de Lima ${ }^{19}$ e de Rodrigues ${ }^{20}$ mostram em seus respectivos trabalhos. Lima ${ }^{19}$ evidencia a intenção das políticas governamentais do chamado Estado Novo em olhar a alimentação do trabalhador como elemento fun- 
damental para promover a produção industrial através da força de trabalho do operário bem alimentado. Rodrigues mostra que a expressão alimentação racional foi fruto do interesse acadêmico articulado às políticas estatais de integração nacional que marcaram a história política do Brasil nesse período. De acordo com esse autor, a expressão alimentação racional ganhou força a partir de 1938 com duas iniciativas editoriais vendidas nas bancas. A primeira intitulava-se Viver!: mensário de força, saúde e beleza, divulgando conhecimentos higiênicos, educacionais e eugênicos, que circulou entre 1938 e 1946 e que publicava desde o primeiro número uma coluna com o título de "alimentação racional". A segunda iniciativa em que o termo apareceu de forma pioneira foi na obra Os pequenos fundamentos da boa alimentação, de Thalino Botelho, na qual a adoção da "alimentação racional" integrava uma lista de sugestões para resolver os problemas alimentares no Brasil. Sant'Anna ${ }^{17}$ mostra a relação estabelecida na época entre boa alimentação e progresso nacional, relevando que o combate à desnutrição e aos maus hábitos alimentares significava um passo importante rumo à modernização do país.

Diferentemente, o conceito racionalidade nutricional ora proposto é um construto mais recente e reúne diferentes aspectos: a prevenção de "risco" representado pela não adoção de dieta nutricionalmente equilibrada ou adequada conforme preconizado pela ciência, em que a maior racionalidade em torno da escolha alimentar superaria a desinformação que envolve os riscos relacionados às doenças e à obesidade; o leitmotiv nas discussões que dizem respeito à saudabilidade e funcionalidade alimentar (muito presentes em atividades de cultura física), assim como nas controvérsias em torno do fast-food e da ingestão de carne, leite, glúten, dentre outros. O movimento de "tirania da saúde", conforme descrito por Camargo Júnior ${ }^{4,5}$ em seu aspecto alimentar e nutricional, pode se expressar desde a redução das quantidades de comida à proibição do uso de determinados alimentos pela possibilidade de desencadearem algum processo patológico. Nesta situação, entende-se a percepção de risco à saúde como uma forma de ausência da mesma, tão importante quanto a manifestação de doença em si ${ }^{21}$.

Os estudos de Maria Lucia Bosi ${ }^{22,23}$ são de alta relevância para a compreensão do sentido que estas expressões - racionalidade alimentar e racionalidade nutricional - podem ter adquirido. Dentre as diversas análises que procedeu, evidencia que o discurso dominante no ensino de
Nutrição é voltado para a consolidação da produção científica ao tratar o processo alimentar e nutricional apenas a partir do enfoque biológico, em detrimento da formação histórica e social de que se reveste. Este acentuado enfoque dado ao biológico culmina com o estado atual de excessiva racionalidade do processo alimentar e nutricional, principalmente por trata-lo apenas sob a ótica fisicalista dos nutrientes e sua relação com o organismo. Considerar tal processo apenas a partir do que acontece dentro de um corpo o destitui da possibilidade de contemplá-lo inserido no contexto da sociedade, cujo bojo oferece inúmeras possibilidades de representação e significação que a comida pode adquirir ao longo das trajetórias entrelaçadas (intersubjetivas) dos indivíduos. Há que se considerar como fundamental para o entendimento de todo o processo alimentar a inegável existencialidade da comida, pois a escolha do que comer é um processo complexo, revestido de características específicas, que perpassa desde a arquitetura cognitiva subjetiva até a afirmação de si mesmo como existente em um mundo dado, obviamente visitando as diferentes organizações que circundam este trajeto, como família, escola, mercado de alimentos, mídia, ciência.

Permeando estas organizações encontram-se tendências contemporâneas regendo as práticas alimentares: mudanças significativas na estrutura das atividades produtivas e empregos com maior prevalência nos setores secundário e terciário da economia; maior participação feminina no mercado de trabalho, ausentando a mulher do preparo das refeições do grupo familiar; avanço tecnológico das indústrias de alimentos com a oferta de refeições semiprontas, proliferação do fast-food. As chamadas 'transições sociais' - nutricional, epidemiológica e demográfica - expressaram o desenvolvimento estrutural, funcional e econômico da sociedade. A contrapartida destas mudanças aponta uma resposta diferenciada aos novos padrões, como a sensível modificação das mesas de refeição e das comidas que se põe às mesas. Enquanto a dona de casa preparava arroz com feijão, salada, "mistura” de carne e legumes, as mesas dos "quilos" oferecem um cardápio inovador, já que o desenvolvimento econômico observado pôde proporcionar acesso a tais inovações gastronômicas.

Apesar da tendência desse estudo em apresentar o conceito de racionalidade nutricional como uma ideia proveniente de acentuada racionalidade em relação às práticas alimentares, a qual pode estar implicada com as diferentes ex- 
pertises envolvidas na produção e no consumo de alimentos, o estudo de Barbosa indica que:

as pessoas são capazes de citar com clareza que alimentos são considerados saudáveis da mesma forma que os vilões dos cardápios. Sabem indicar, também, aquilo que elas gostam de comer e aquilo que do ponto de vista da saúde seria preferivel ingerir, e as estratégias que usam para lidar com todas estas ambiguidades e contradições ${ }^{24}$.

Longe de dúvidas, haverá controvérsias na construção e apreciação do conceito de racionalidade nutricional e que repousarão, principalmente, na influência que diferentes expertises poderão exercer sobre as práticas alimentares. Mas, para além desta controvérsia, o alerta pretende ir de encontro à atitude ingênua de não reconhecer a emergência deste fenômeno, o qual, revestido de "verdade científica", acaba por substituir a simplicidade original das refeições por construtos provenientes de entidades sociais com interesses mercadológicos oriundos do sistema econômico. Como simplicidade original nos referimos ao sentido mais rudimentar e/ou tradicional atribuído às refeições, isento da problemática de risco alimentar ou preocupação com a funcionalidade ou ainda equilíbrio nutricional dos alimentos. Refeições tomadas com o propósito de potencializar encontros e reuniões familiares e que facultam aos sujeitos o enredamento de seus projetos existenciais. Atualmente, tanto por conta do maior cuidado alimentar como por aquelas outras transformações sociais, os encontros em torno das refeições parecem estar sendo substituídos por novas práticas que subtraem dos sujeitos esta proximidade descontraída, tão peculiar entre pessoas que realizam de fato um encontro.

\section{A medicalização da alimentação}

Os tempos atuais são artífices da supervalorização da saúde, tratada atualmente como vulnerabilidade complexa, cujas diversas especificidades o sujeito comum não saberia dar conta - é "necessário" um tipo de expertise ${ }^{25}$ para cada forma de cuidado com o corpo. Este passa a simbolizar em sua "saudabilidade" aparente a maior expressão de racionalidade e aplicação do conhecimento que diferentes expertises produzem em função das inovações do mercado.

A desestruturação da alimentação apontada por Claude Fischler ${ }^{26}$ na década de 1980 com o conceito de gastro-anomia, de certo modo facilitou a consolidação de advertências médicas acerca da alimentação praticada pelo indivíduo já que, uma vez ausente qualquer regra alimen- tar, mesmo aquelas de valor simbólico, criou-se a brecha para o surgimento de novas, cujos interesses são alheios ao indivíduo, como aquelas veiculadas na publicidade de alimentos, as quais atuam na elaboração do desejo individual expresso como "escolha alimentar" (ressalta-se que este fato é facilitado pelo processo de comoditização da ciência, processo a ser explorado mais adiante, o qual se empenha na produção de informações que promovam determinados produtos alimentares, como os alimentos funcionais).

Acompanhando este processo, aponta-se o surgimento recente de novas práticas associadas à saúde, pautadas na valorização da "tríade beleza-vigor-juventude" 27 , que tomam como referencial de saúde a boa forma e o bem estar, e que têm como palco principal as academias de ginástica. Estas passam a desempenhar papel relevante no processo de medicalização da alimentação, a partir do momento em que se prestam a aumentar a performance dos praticantes de esportes ou atividade física, em busca de modificações corporais pautadas nesta tríade.

A alimentação, antes tomada como ponto de encontro familiar - a refeição - agora é concebida como uma das vias de conquista da "saúde", a qual se deslocou para a prática (mágica) de consumir elementos que, a título de serem eficazes no melhoramento fisiológico, desincumbem sujeito e sociedade de resoluções existenciais de maior empenho.

Os alimentos funcionais ou nutracêuticos ${ }^{28}$ adquiriram, dentro da idealização de sistemas alimentares, equivalência axiológica às drogas medicamentosas, aproximando as ideias de medicalização da alimentação e farmacologização desta. Assim, há que se considerar também o surgimento de práticas alimentares constituídas sobre o pressuposto de que há uma racionalidade alimentar e nutricional consolidada pela expertise em torno do conceito de alimentos funcionais, a qual parece legitimar a grande utilização de produtos promovidos pelo merchandising de alimentos que possam ser enquadrados na categoria de funcionais.

Esse aspecto da racionalidade nutricional encontra certa proximidade do que $\mathrm{Luz}^{29}$ propõe em relação à racionalidade médica e às cinco dimensões interligadas: morfologia, fisiologia, diagnose, terapêutica e doutrina médica. Em relação à racionalidade nutricional, a dimensão terapêutica relaciona-se quase que intimamente ao aspecto da funcionalidade alimentar em sua proposta de resolver o que é visto ou tratado como "problema"; a nutrição funcional responde a esse 
modo mais terapêutico e intervencionista de tratar a alimentação. A morfológica de como o corpo é estudado dentro do processo alimentar e a dimensão fisiológica diria respeito propriamente às características nutricionais do alimento.

A comoditização da ciência é um processo que, entre outras coisas, procura atender o interesse capitalista em desenvolver produtos que vão ao encontro dos interesses do novo perfil de consumidores. Em alguns casos presenciam-se certas distorções que as informações acerca de alimentação e de nutrição vêm sofrendo com este processo, o qual aponta mecanismos que visam atender interesses de setores ligados à produção de itens de consumo pessoal, fato dissonante a uma visão tradicional de ciência tomada como "forma de saber objetiva e verdadeira, (...) dotada de um método capaz de garantir a aquisição de um conhecimento universal, necessário e inovador" ${ }^{30}$. Como exemplo de distorções vejamos as porções individuais de alimentos rápidos cujo argumento de convencimento é o fato de serem "próprios ou adequados" para o consumo concomitante a outras atividades, como dirigir, digitar, falar ao telefone e que suas porções singulares afirmam conter os requerimentos energéticos e nutricionais de uma refeição (!). E o sentar à mesa e comer, como fica? Aqueles interesses parecem confundir o bem-estar físico com um outro tipo, este último proporcionado pelo desejo fomentado pela indústria midiática de adquirir produtos que privilegiem qualidades pessoais, em detrimento de qualidades ou características que apresentem seu valor no convívio social, como é o caso da comensalidade. Tais interesses podem estar levando a alimentação e, em última instância, a saúde, à condição de mera mercadoria e não como um direito do cidadão de sentir-se bem, com disposição para a vida, para o amor, para o trabalho, criativo para enfrentar as batalhas cotidianas ou eventuais, as desventuras, as infelicidades. Este deveria ser o conceito amplo de saúde a ser defendido porque vai ao encontro do projeto existencial do sujeito, e não o estado de não doença e prevenção de riscos através de produtos da indústria do bem-estar.

\section{O papel do nutricionista na medicalização da alimentação}

De acordo com Prado et al. ${ }^{31}$, os estudos da Nutrição, enquanto um campo do conhecimento humano, atribui um sentido ao comer predominantemente racionalizado e biologicista, característico da concepção biomédica hegemônica no âmbito da saúde e desvinculado das questões sociais acerca do alimento e do comer. O nutrir e a dieta são concebidos de modo a estarem voltados ao funcionamento e à fisiologia do corpo humano biológico e desprovidos de vínculos ou implicações sociais, o que corresponde ao reducionismo característico do modelo biomédico clássico, que reduz a saúde apenas à condição de ausência de doenças ${ }^{4,5}$; além de limitar todo o processo terapêutico do nutricionista apenas à prescrição de uma dieta baseada exclusivamente em características nutricionais, muitas vezes não considerando a multidimensionalidade do ato de alimentar-se a si mesmo e a outrem ${ }^{32}$.

Este modelo de prescrição de dieta contribui para a elaboração de novas práticas alimentares, moldadas na busca por um aumento de performance humana, baseadas em determinadas características de alguns nutrientes ou compostos funcionais específicos, seguindo um modelo de alimentação medicalizado e farmacologizado. Este modelo é cada vez mais amparado e apoiado pela atuação do nutricionista, profissional responsável pela transmissão ao público leigo dos conhecimentos científicos que subsidiam este novo modelo de alimentação, cada vez mais distanciado de sua multidimensionalidade original.

A alteração das práticas alimentares pela atuação do nutricionista, por vezes, deixa a esfera da prevenção e passa a ser vista como uma intervenção rígida, secundada pela mídia, e que transforma o risco em quase-doença. Passa, a partir desta instância, a ser parte do controle da vida cotidiana através de normatizações em saúde, de acordo com o modelo biologicista e reducionista em voga na formação profissional. Para alguns autores o modelo restritivo das intervenções no campo da alimentação pode ser vistos como um processo de racionalização e medicalização da dieta ${ }^{11}$.

Relevante acentuar o papel que a indústria de alimentos/farmacêutica desempenha em fomentar a medicalização da comida ao apresentar seus compostos funcionais com o propósito de atender às novas necessidades de saúde, baseadas na tríade beleza-vigor-juventude, criando um nicho mercadológico muito lucrativo para estas indústrias. Com o propósito de aumentar a performance dos consumidores (enhancement, segundo Peter Conrad), alimentos ou suplementos nutricionais são comercializados com intenso processo de marketing direto a eles ou através da orientação profissional, secundada por processo de marketing direcionado a este, em processo similar ao desenvolvido pela indústria farmacêutica para estimular o consumo de medicamentos ${ }^{33}$. 
Pode-se vislumbrar este fenômeno ao observar-se a participação cada vez maior de indústrias de alimentos ou farmacêuticas em eventos direcionados aos profissionais nutricionistas. Em estratégia similar à utilizada pela indústria farmacêutica na consolidação do Complexo Médico-Industrial, a indústria de alimentos vem apoiando e financiando pesquisas ou utilizando alguns outros subterfúgios, como o recrutamento de experts em determinadas áreas de conhecimento para atuar como consultores, ou patrocinando eventos científicos direcionados, como citado anteriormente. Essas estratégias geram efeitos positivos à indústria de alimentos, como interpretações mais favoráveis dos estudos científicos; posições privilegiadas em recomendações de organizações profissionais, ou simplesmente a acepção, por parte da opinião pública, de que a indústria está investindo na busca de produtos melhores ${ }^{30,33}$.

No entanto, esses produtos são comercializados mediante estímulos publicitários para um aumento significativo de seu consumo, que supervalorizam os seus supostos novos benefícios ${ }^{33}$. A indústria de alimentos, a partir do marketing e do fomento às pesquisas científicas, em atitude similar à indústria farmacêutica, vem também influenciando o meio científico na construção de novos conceitos sobre dieta saudável.

\section{Conclusão}

Comer é função humana dependente de um complexo de atividades de cunhos econômico, político, social, cultural, existencial, fisiológico. Além disso, é (ainda) um ato que resulta de decisões subjetivas, as quais são impregnadas da história pessoal do sujeito. É atividade que tem a peculiaridade de, além de garantir sua fisiologia, assegurar também a sua humanidade, pois o que se come, o como e o quando se come, são elementos repletos de significações, porque a vida humana só ganha sentido através do dinamismo das relações sociais. São referenciais todos os processos que propiciam a alimentação, pois ingerir alimentos por si só nem sempre é atitude suficiente para garantir a nutrição, se não for levado em conta a fenomenologia peculiar e anterior a esta função específica, uma vez que a contingência da prática alimentar não é restrita ao mapeamento científico do saudável e nutritivo. Transborda para a esfera da subjetividade e da representação que a comida implica, o que na maioria das vezes não coaduna com considerações cognitivas. Neste âmbito, elementos subjetivos como desejo, prazer, relações entre sujeitos são mais relevantes do que o saber, o dever ou o querer (enquanto categorias expressas da probabilidade de decisão).

$\mathrm{O}$ consumo de alimentos funcionais aponta para um padrão alimentar que está sendo traçado por expertise surgida a partir do grande número de alimentos com propriedades específicas que vêm sendo lançado no mercado de alimentos, o que acaba por estimular uma sociedade cada vez mais fundamentada no conhecimento.

As inovações na produção de novos alimentos têm despertado o interesse de setores específicos de investimentos, como o agronegócio e a publicidade, principalmente em vista da força que a política de inovação tecnológica tem emprestado ao setor, principalmente pela demanda de alimentos com propriedades benéficas à saúde, incluindo prevenção e tratamentos a doenças. Com a disseminação para o grande público de estudos científicos e resultados de pesquisas, que apontam para o papel da alimentação na promoção de um novo modelo de saúde (que busca a supernormalidade e trata o risco como doença), e considerando o importante papel de credibilidade desempenhado pela ciência em geral, no novo modelo de sociedade contemporânea, observa-se que a funcionalidade dos alimentos vem sendo explorada por setores (como a indústria de alimentos e o ramo da publicidade) em busca de criação de novas necessidades nutricionais e alimentares na população, gerando novas demandas alimentares e/ou nutricionais (como por exemplo, suplementos), até então inexistentes.

Seguindo esse "andar da carruagem", a saúde, antes tratada como bem constituído também e, principalmente, pelo sujeito existente através de seu projeto de vida, parece ser resultado de um conjunto de fórmulas e prescritos racionais de alimentos com funcionalidades que "promovem" seu melhoramento. O preocupante é que, com isso, pode-se perder de vista a simplicidade do almoço em família ou do petisco entre amigos, práticas tradicionalmente tomadas como, no mínimo, atitudes de vida saudável. 


\section{Colaboradores}

MR Viana, AS Neves, KR Camargo Júnior, SD Prado e ALO Mendonça trabalharam juntos em todas as etapas de produção do manuscrito.

\section{Referências}

1. Beardsworth A, Keil T. Sociology on the menu. London: Routdedge; 1997.

2. Nestlé M. Food Politics. Berkeley: University of California; 2002.

3. Conrad P. The medicalization of society: on the transformation of human condition into treatable disorders. Baltimore: The Johns Hopkins University Press; 2007.

4. Camargo Junior KR. As armadilhas da concepção positiva de saúde. Physis 2007; 17(1):63-76.

5. Camargo Júnior KR. Medicalização, farmacologização e imperialismo sanitário. Cad Saude Publica 2013; 29(5):844-846.

6. Canto-Sperber M, organizador. Dicionário de ética e filosofia moral. São Leopoldo: Ed. Unisinos; 2003.

7. Marías J. Introdução à Filosofia. São Paulo: Duas Cidades; 1966.

8. Hassel CA. Reconsidering Nutrition Science: critical reflection with a cultural lens. Nutrition Journal 2014; 13:42.

9. Röd W. O Caminho da Filosofia. Amaral. Brasília: Ed. UnB; 2008.

10. Marías J. História da filosofia. São Paulo: Martins Fontes; 2004.

11. Navolar TS, Tesser CD, Azevedo E. Contributions to the construction of Integrative and Complementary Nutrition. Interface (Botucatu) 2012; 16(41):515-527.

12. Mathé T, Pilorin T, Hébel P. Du discours nutritionnel aux représentations de l'alimentation. Paris: Crédoc; 2008. Chiers de Recherche no 252.

13. Mol A. Mind your plate! The ontonorms of Dutch dieting. Social Studies of Science 2013.

14. Pollan M. Em defesa da comida, um manifesto. Rio de Janeiro: Intrínseca; 2008.

15. Contreras J, Gracia M. Alimentação, sociedade e cultura. Rio de Janeiro: Fiocruz; 2011.

16. Carvalho MC, Luz MT, Prado SD. Comer, alimentar e nutrir: categorias analíticas instrumentais no campo da pesquisa científica. Cien Saude Colet 2011; 16(1):155163.

17. Sant'Anna DB. A cultura na ponta do garfo: estética e hábitos alimentares na cidade de São Paulo 1890/1920. Cadernos PAGU 2012; 39:177-200.

18. Vasconcelos FAG, Calado CLA. Profissão nutricionista: 70 anos de história no Brasil [Internet]. Campinas. 2011 [acessado 2012 jun 7]; 24(4). Disponível em: http://www.scielo.br/scielo.php?script=sci_arttext\&pi$\mathrm{d}=$ S1415-52732011000400009\&lng=en\&nrm=iso

19. Lima ES. Gênese e Constituição da Educação Alimentar: uma síntese. Physis 1997; 7(2):9-29.

20. Rodrigues J. A “alimentação racional”: uma proposta de mudança nas práticas alimentares durante o Estado Novo (1937-1945). In: Anais do XXIV Simpósio Nacional de História - História e multidisciplinaridade: territórios e deslocamentos. São Leopoldo: Unisinos; 2007. CD-ROM.

21. Rosa R. Ciência, saúde e subjetividades individuais: os públicos da saúde [Internet]. 2012 set [acessado 2014 set 2]; 6(3). Disponível em: www.reciis.icict.fiocruz.br

22. Bosi MLM. A Face Oculta da Nutrição: Ciência e Ideologia. Rio de Janeiro: Ed. UFRJ, Espaço e Tempo; 1988.

23. Bosi MLM. Profissionalização e Conhecimento: a nutrição em questão. São Paulo: Hucitec; 1996. 
24. Barbosa L. Feijão com arroz e arroz com feijão: o Brasil no prato dos brasileiros. Horizontes Antropológicos 2007; 13(28):87-116

25. Collins H, Evans R. Repensando a Expertise. Belo Horizonte: Fabrefactum; 2010.

26. Fischler C. Gastro-nomie et gastro-anomie: sagesse du corps et crise bioculturelle de l'alimentation moderne [Internet]. Paris: Communications (31); 1979 [acessado 2014 fev 17]. Disponível em: http://www.persee. fr/web/revues/home/prescript/article/comm_05888018_1979_num_31_1_1477

27. Nascimento MC, Barros NF, Nogueira MI, Luz MT. A categoria racionalidade médica e uma nova epistemologia em saúde. Cien Saude Colet 2013; 18(12):35953604.

28. Vizzotto M, Krolow AC, Teixeira FC. Alimentos Funcionais: conceitos básicos. Pelotas: Empresa Brasileira de Pesquisa Agropecuária, Ministério da Agricultura, Pecuária e Abastecimento, Embrapa Clima Temperado; 2010.

29. Luz MT. Natural, Racional, Social: razão médica e racionalidade científica moderna. $3^{\mathrm{a}}$ ed. São Paulo: Hucitec; 2012.

30. Mendonça ALO, Camargo Júnior KR. O complexo médico industrial no contexto da comoditização da ciência: relativizando o relativismo. Rev Brasileira de Ciência, Tecnologia e Sociedade 2011; 2(2):7-31.

31. Prado SD, Bosi MLM, Carvalho MCVS, Gugelmin SA, Mattos RA, Camargo Júnior KR, Klotz J, Delmaschio KL, Martins MLR. Alimentação e Nutrição como campo científico autônomo no Brasil. Rev Nutr 2011; 24(6):927-937.

32. Prado SD, Bosi MLM, Carvalho MCVS, Gugelmin SA, Silva JK, Delmachio KL, Martins MLR. A pesquisa sobre Alimentação no Brasil: sustentando a autonomia do campo Alimentação e Nutrição. Cien Saude Colet 2011; 16(1):7-17.

33. Williams S, Martin P, Gabe J. The pharmaceuticalisation of society? A framework for analysis [Internet]. Sociology of Health \& Illness 2011 [acessado $2013 \mathrm{dez}$ 12]; 1-16. Disponível em: http://dx.doi.org/10.1111/j. 1467-9566.2011.01320.x

Artigo apresentado em 17/05/2015

Aprovado em 14/03/2016

Versão final apresentada em 16/03/2016 